Potter, A., Lalwani, C., Disney, S.M., Velho, H., (2016), "Modelling the impact of factory gate pricing on transport and logistics",

in "Developments in Logistics and Supply Chain Management: Past, Present and Future", Edited by Pawar, K.S., Rogers, H., Potter, A., and Naim, M.M., Palgrave Macmillan UK, pp231-239, ISBN: 978-1-349-55848-3.

\title{
MODELLING THE IMPACT OF FACTORY GATE PRICING ON TRANSPORT AND LOGISTICS
}

\author{
Andrew Potter ${ }^{1}$, Chandra Lalwani ${ }^{1}$, Stephen Disney ${ }^{1}$ and Helder Velho ${ }^{2}$ \\ ${ }^{1}$ Logistics Systems Dynamics Group, Cardiff Business School, Cardiff University \\ ${ }^{2}$ Tesco plc, Hatfield
}

\begin{abstract}
Over the past year, one of the biggest issues to arise in the UK grocery distribution industry is that of Factory Gate Pricing (FGP). The use of FGP within the grocery sector is one of the largest applications of the concept. This paper quantifies the efficiency gains that can be achieved by redesigning the inbound distribution network. An action based research approach has been taken, working directly with a major UK retailer, which was the first grocery company to adopt FGP. Our methodology involved interviews with relevant personnel and modelling. The results found that the use of consolidation networks for less than truckload consignments resulted in a reduction of $25 \%$ in the vehicle miles required to get ambient products from suppliers to the distribution centres, and $23 \%$ for fresh products. The paper concludes that, with greater coordination of the inbound logistic flows for grocery retailers, there is the potential to deliver a significant reduction in transport demand with both economic and environmental benefits.
\end{abstract}

\section{INTRODUCTION}

Over the past 30 years, the grocery supply chain has evolved considerably in the drive to reduce costs and improve the service level provided to customers. The 1970s and 1980s saw the development of distribution centres (DC) for ambient products, with retailers taking over responsibility for deliveries to their stores. The 1990s brought the introduction of consolidation centres to reduce the level of transport demand required to deliver products to the DCs (Finegan, 2002). The latest development is for retailers to take control of the delivery of goods into their DCs. This movement has gained momentum recently and is known as Factory Gate Pricing. The evolution of grocery distribution is shown in Figure 1.

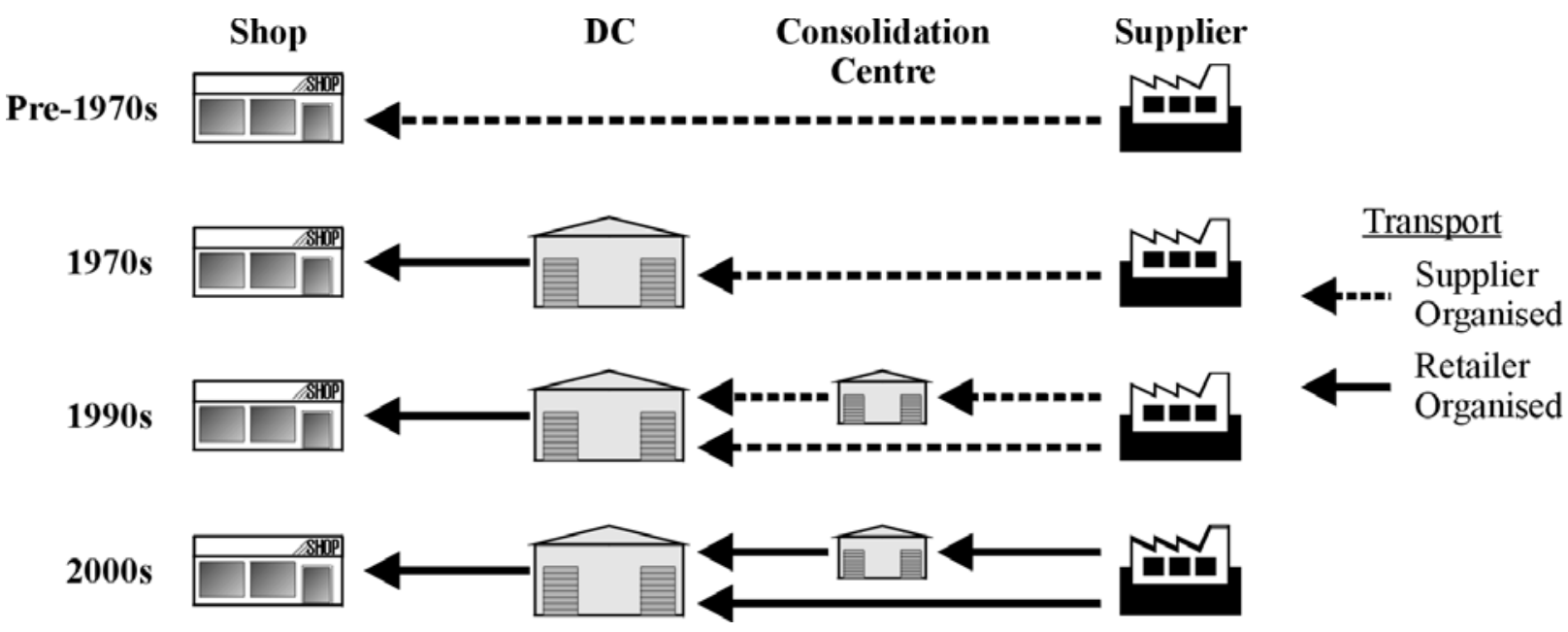

Figure 1: The evolution of grocery distribution (based on Finegan, 2002) 
Potter, A., Lalwani, C., Disney, S.M., Velho, H., (2016), "Modelling the impact of factory gate pricing on transport and logistics",

in "Developments in Logistics and Supply Chain Management: Past, Present and Future", Edited by Pawar, K.S., Rogers, H., Potter, A., and Naim, M.M., Palgrave Macmillan UK, pp231-239, ISBN: 978-1-349-55848-3.

Having taken control of their inbound logistics, retailers are looking at further improving their efficiency by increasing the backloading of store delivery vehicles and the consolidation of smaller loads into consolidation centres. The aim of this paper is to demonstrate how the increased use of consolidation centres in the inbound network can be modelled and to quantify the impact on transport demand in both the ambient and fresh networks of a major UK retailer. The paper proceeds by firstly providing more details about Factory Gate Pricing, before describing the case study company. The method adopted as part of the task force is then outlined, including details on the modelling process. The results of this modelling are then presented and conclusions are drawn.

\section{FACTORY GATE PRICING}

The concept of Factory Gate Pricing (FGP) has a long tradition. In international trade, exworks is an accepted trade term that has the same implications as FGP. Domestically, one of the first sectors to pioneer the concept was the fashion industry in the early 1990s (Lewis, 2002) in response to the need to improve delivery times. It has also been used in the automotive sector for the supply of parts to manufacturers (Brown, 2002b). However, the application of FGP to the UK grocery sector represents probably the most complex application yet. Tesco were the first to implement it and Sainsbury's has followed their lead while Asda and Carrefour have established processes similar to FGP. Its implementation has triggered a broad debate in both trade and professional journals - for instance, see Beevor (2002), Meczes (2002), and Rowat (2002).

FGP has been defined as "the establishment of a price for completed goods excluding transport costs" (Finegan, 2002). However, the term has seen a wider use in referring to both the contractual arrangements and the physical movement of the products to the DCs. Under FGP, the retailer takes over control of the transport of the goods from the supplier. This may involve an outside contractor or the use of store delivery vehicles for backhauling. Either way, the aim is to make the best use of the available vehicles, with the retailer coordinating flows to provide loads in both directions. In light of this, a broader definition of FGP is the use of an ex-works price for a product and the organisation and optimisation of transport by the purchaser to the point of delivery.

A number of reasons have been put forward as to why FGP has become a reality in the grocery sector. Until recently, one of the constraints was lack of computer packages capable of managing the many flows involved in grocery distribution. With these tools now available, the necessary infrastructure can be provided (Lewis, 2002). This has provided the catalyst for the implementation of FGP by the retailers, with five main drivers behind the move:

- Price transparency - by being able to separately identify the costs of both freight and products, these can then be managed more easily by the retailer (Kyle, 2002).

- Maximisation of the use of vehicle capacity - by managing all of the flows together, retailers can consolidate movements to reduce transport demand (Lewis, 2002).

- Cost reduction - in an industry with tight margins, this is important and decreasing the demand for transport will reduce transport costs (Rowat, 2002).

- Green issues - retailers are becoming increasingly aware of their environmental responsibilities and reducing transport is environmentally beneficial (Lewis, 2002).

- Improved delivery reliability - By managing inbound deliveries directly, it is easier for retailers to ensure on time deliveries (Brown, 2002a). 
Potter, A., Lalwani, C., Disney, S.M., Velho, H., (2016), "Modelling the impact of factory gate pricing on transport and logistics", in "Developments in Logistics and Supply Chain Management: Past, Present and Future", Edited by Pawar, K.S., Rogers, H., Potter, A., and Naim, M.M., Palgrave Macmillan UK, pp231-239, ISBN: 978-1-349-55848-3.

\section{CASE STUDY - TESCO}

Tesco is the largest grocery retailer in the UK, with 759 stores, annual sales of $£ 25.6$ billion and a market share of $25.8 \%$ (Osborne, 2003). They were the first company in the UK grocery sector to move towards FGP in late 2001. Overall, the ambient network handles 168,000 pallets per week whilst 135,000 pallets pass through the composite network. Before FGP some consolidation of incoming deliveries took place, equating to about $3 \%$ of ambient volume and $34 \%$ of fresh products. Once complete, approximately $20 \%$ of ambient and $40 \%$ of composite products will be consolidated before delivery to the DC. Initially, FGP has been implemented within the UK supplier base. Implementation for deliveries from Europe will take place in due course.

To support the management of inbound deliveries, a new network of consolidation centres is being established and the design of this network is the focus of this paper. At an operational level, extensive use has been made of IT solutions to enable the management of the inbound movements. A single, integrated software package selects the most appropriate channel of distribution and haulier for every load, informing hauliers electronically across the Internet. This combination of haulier management and extensive IT use means that the distribution team in Tesco has practically become a fourth party logistics company (4PL).

\section{METHODOLOGY}

In order to carry out the work, a task force approach was taken. With this, a member of the research team spent several months working closely with the distribution team. As well as providing the necessary information for the modelling work, this also offered the opportunity to get an understanding of how the overall process worked. One of the aims of the task force was to validate the design of the consolidation centre networks, work that was initially carried out by Tesco.

The modelling work used a network planning computer package. The programme allows the design of distribution networks and the testing of different structures to produce a best solution. The software makes a number of assumptions when carrying out the modelling, including demand being spread evenly across time, 100\% availability at the supplier and a constant average speed for the vehicle. The data used in the model provided detailed information as to the volume of product from each supplier to every DC. Suppliers were contacted by telephone in order to identify the source points for the products. A strategic decision was taken to route those that supplied at least 18 pallets per day per DC direct to the DC. In effect, these were treated as full truckload consignments and removed from the data set accordingly. The remaining data covered less than truckload consignments only. Costs were based on current charges and levied on a per mile basis for transport costs and per pallet basis for handling charges at the consolidation centres.

The validation process initially involved reviewing the process undertaken by Tesco to design the consolidation network. This relied on archival evidence and also interviews with the personnel that undertook the work. By comparing the process with other work undertaken on network design (for example, Hammant et al., 1999), the robustness of the process could be assessed. From this assessment, an area for improvement was identified in the design of the model. The Tesco version required constraints to be imposed for certain conditions, removing some of the decision-making capabilities of software package. Therefore, the structure was redesigned to allow these decisions to be made by the model and the Tesco results were cross-checked against this new design. 
Firstly, the least cost number of consolidation centres was identified. Centre of gravity modelling was used to identify potential structures and the transport and handling charges calculated accordingly. Recognising that the software will only produce good scenarios rather than the optimum, the modelling was repeated 5 times for each number of consolidation centres and the best result selected. It was then necessary to confirm that the solution proposed by Tesco was amongst the best possible solutions. Therefore, the locations of their consolidation centres were entered into the new model structure. The results were compared both against the option of all suppliers servicing the DCs direct, the 'As Is' scenario and the solution from the centre of gravity analysis.

\section{CENTRE OF GRAVITY RESULTS}

In the centre of gravity analysis, it was decided to look at structures for ambient products with between 5 and 10 consolidation centres, while the composite network was tested between 7 and 11 centres. These boundaries were chosen given the practical considerations of establishing and managing the network. The results of this analysis can be found in Table 1 . To protect confidentiality, the costs have been normalised with the cost for the lowest number of consolidation centres being made equal to 100 .

\begin{tabular}{|c|c|c|c|c|}
\hline \multirow{2}{*}{$\begin{array}{l}\text { Number of } \\
\text { consolidation } \\
\text { centres }\end{array}$} & \multicolumn{2}{|c|}{ Ambient Products } & \multicolumn{2}{c|}{$\begin{array}{c}\text { Composite Products } \\
\text { Average } \\
\text { Colume }\end{array}$} \\
\hline \hline 5 & 100 & Average Volume & & \\
6 & 98.0 & 4299 & & \\
7 & 97.9 & 3793 & 100 & 9350 \\
8 & 95.5 & 3357 & 97.8 & 8524 \\
9 & 96.0 & 2974 & 99.0 & 7534 \\
10 & 95.3 & 2706 & 99.6 & 6871 \\
11 & & & 100.2 & 6137 \\
\hline
\end{tabular}

\section{Table 1. Average cost and volume against number of consolidation centres}

The ambient results do not appear to reach a minimum, cost continuing to fall as the number of consolidation centres increases. However, there are other factors that need to be taken into consideration in reaching a conclusion as to the best solution. In particular, the model is assuming the handling charge is constant regardless of volume. In reality, economies of scale would be present. Therefore, the handling charge is likely to be lower the higher as volume increases. For the ambient network, Tesco decided upon 6 consolidation centres, as it seemed reasonable to conclude that this delivers a low cost solution. For composite products, there is a U-shaped curve to the costs, which reaches a minimum at 8. Even allowing for economies of scale, the curve would still reach a minimum around this value. These findings agree with the results found by Tesco, and so validates their solution.

\section{NETWORK VALIDATION RESULTS}

Figure 2 compares the locations identified by Tesco as offering a low cost solution and the results from the validation exercise. Both solutions have a certain degree of synergy, with some consolidation centres being located close to each other. In the composite and ambient solutions there are two exceptions. These can be largely attributed to the different model structures. In the ambient network, there are DCs close to both Bristol and Milton Keynes. Consequently, material for these is delivered direct rather than through a consolidation centre. 
This affects the centres of gravity by effectively removing them from the calculations. The same is true for the composite network, with DCs in the Bristol and Cambridge areas allowing the consolidation centres to be located elsewhere. From these results, the decision has been taken by Tesco to introduce a ninth consolidation centre at Portsmouth, a location identified in the validation model.
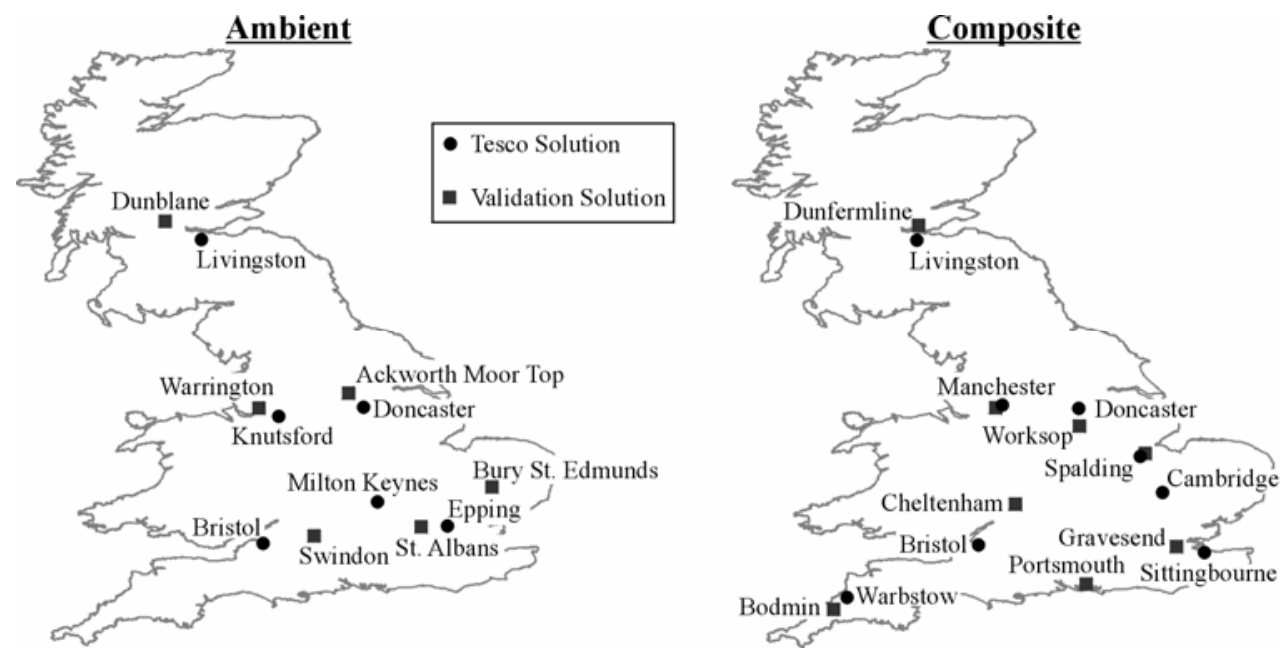

Figure 2. The location of the consolidation centres for ambient and composite products

While the maps indicate that there is a case for moving some of the consolidation centres, it is necessary to quantify the benefits that such a move would bring. This was done using the modelling software to route the products through the network, enabling the level of transport demand (in terms of miles travelled), total cost and volume to be ascertained. The results of this analysis compared against both direct supply and the 'As Is' scenario can be found in Table 2.

As can be seen, the introduction of consolidation centres during the 1990s has had some impact upon the demand for transport, with small reductions for both ambient and composite networks. In terms of cost, there has been very limited reduction. However, these figures only take into consideration transport and handling charges and do not include an allowance for factors such as reduced DC congestion. With the move to FGP, it can be seen that there are significant gains in both transport demand and cost. For the ambient network, the Tesco solution will reduce the number of transport miles by $25.3 \%$, whilst the validation model would offer a $27 \%$ reduction. This large reduction can be attributed to the significant increase in ambient products that will be routed through consolidation centres in the new network. The Tesco solution will also reduce distribution costs by $13.9 \%$. For composite products, similar gains will be made. The Tesco network (before the inclusion of Portsmouth) will reduce transport miles by $23 \%$ and cost by $17.2 \%$. By comparison, the validation model would reduce transport miles by $23.4 \%$ and cost by $17.4 \%$, despite the increase in volume being less than before. This is because the management of the network will be coordinated centrally and flows routed through the shortest and most cost effective route. It can therefore be said that the network designed by the validation model offers little benefit over that produced by Tesco. In terms of the total savings when compared against a network without consolidation centres, transport miles are reduced by $26.9 \%$ for ambient and $27.7 \%$ for fresh products while cost savings of $14.2 \%$ and $14.8 \%$ respectively are predicted. 
Potter, A., Lalwani, C., Disney, S.M., Velho, H., (2016), "Modelling the impact of factory gate pricing on transport and logistics", in "Developments in Logistics and Supply Chain Management: Past, Present and Future", Edited by Pawar, K.S., Rogers, H., Potter, A., and Naim, M.M., Palgrave Macmillan UK, pp231-239, ISBN: 978-1-349-55848-3.

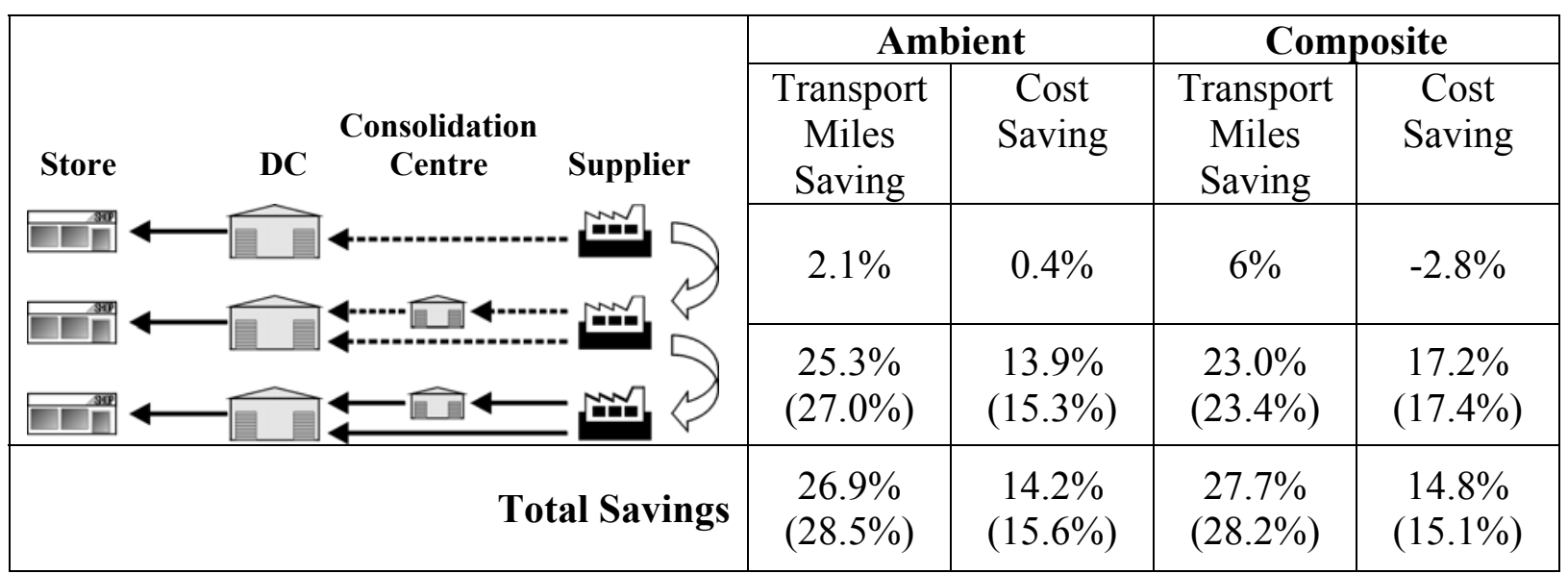

Figures in brackets represent the results from the validation model network as opposed to the Tesco solution

Table 2. The transport miles, cost and volume split for ambient and composite products

\section{CONCLUSIONS}

The concept of Factory Gate Pricing is the latest development to be implemented within the grocery supply chain. Retailers are now responsible for the organisation and optimisation of transport from suppliers to the retailer DCs, paying an ex-works price for the product. Developments in information technology have provided the infrastructure for this change, while the drivers behind its implementation include price transparency, greater use of vehicle capacity, cost savings, environmental concerns and improved delivery reliability. Tesco were the first grocery company in the UK to implement FGP and will use a network of consolidation centres to improve the efficiency of inbound deliveries. The validation of this network design has been reported in this paper. There will be a reduction of around $28 \%$ in the mileage accumulated in transporting less than truckload consignments to DCs, equating to over 400,000 miles per week, as a result of the increased use of consolidation centres. This has significant economic and environmental benefits. Future work will look at confirming that the transport improvements predicted are actually being achieved within the consolidation network and to include store deliveries and backhauling within the model.

\section{REFERENCES}

Beevor D (2002) Factory Gate Pricing Truck Magazine 21st November

Brown A (2002a) Tesco takes control of transport to rdcs Motor Transport 28th February p6 Brown A (2002b) Feeding the Big Cats Motor Transport 25th April pp20-21

Finegan N (2002) Backhauling and Factory Gate Pricing, Watford:IGD Business Publications

Hammant J, Disney SM, Childerhouse P and Naim MM (1999) Modelling the consequences of a strategic supply chain initiative of an automotive aftermarket operation International Journal of Physical Distribution and Logistics Management 29(9) 535-550

Kyle B (2002) Factory Gate Transparency not Pricing Logistics and Transport Focus 4(8) 1923

Lewis C (2002) Everything you could want at your local grocer - even groceries Distribution Business 15(3) 23-25

Meczes R (2002) The gates of hell? Motor Transport 18th April pp14-15

Osborne A (2003) Morrison pops Safeway in its basket The Daily Telegraph 10 January p35

Rowat C (2002) Backhauling and Factory Gate Pricing Logistics and Transport Focus 4(4) $65-68$ 